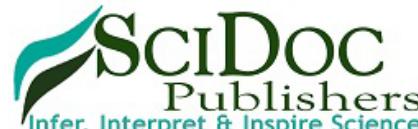

\author{
International Journal of Dentistry and Oral Science (IJDOS) \\ ISSN: 2377-8075
}

\title{
A Comparative Evaluation Of Canine Retraction and Anchor Loss using Ceramic and Stainless Steel MBT Pre-adjusted Edgewise Brackets using Three Dimentional Finite Element Method
}

Trupti Sadhunavar ${ }^{1 *}$, Tejashri Pradhan², Sumedh Deshpande ${ }^{3}$, Aarti Sethia ${ }^{3}, K_{\text {Kanhoba Mahabaleshwar Keluskar }}{ }^{4}$

${ }^{1}$ Lecturer, Department of Orthodontics, KLE VK Institute of Dental Sciences, KAHER, Belagavi, India.

${ }^{2}$ Professor and Head, Department of Orthodontics, KLE VK Institute of Dental Sciences, KAHER, Belagavi, India.

${ }^{3}$ Postgraduate Student, Department of Orthodontics, KLE VK Institute of Dental Sciences, KAHER, Belagavi, India.

${ }^{4}$ Professor at Department of Orthodontics, KLE VK Institute of Dental Sciences, KAHER, Belagavi, India.

\section{Abstract}

Background and Objectives: Simulation of orthodontic force can provide crucial insights on design and implications of orthodontic apparatus like brackets. Ceramic brackets although aesthetic, can create frictional resistance with orthodontic wires. Hence, this study employed Finite element method to evaluate and compare the canine retraction and anchor loss facilitated by pre-adjusted edgewise ceramic brackets and conventional metal bracket systems.

Materials and Method: The study model was generated using the CBCT with favourable conditions of first premolar extraction for orthodontic correction. Finite element model of the maxilla and the teeth were simulated using the MIMICS software. A force of 50 grams was applied for canine retraction with elastomeric chain using preadjusted MBT (MacLaughlin, Bennet and Trevisi system) edgewise brackets of ceramic and metal respectively. ANSYS software was used for the analysis to evaluate the rate of canine retraction, anchor loss and stress generated.

Results: The effective tooth displacement, von Mises stress and stress simulated by FEM were comparatively greater inthe metallic, than inthe ceramic brackets. During retraction, distal, lingual and intrusive displacement of canine was visualised to be greaterwith metallic bracketsin comparison to their ceramic counterparts. Metallic wire and bracket featured the same Young's modulus as they are made of similar materials hence, the force applied led to a greater retraction of canine, unlike ceramic brackets.

Conclusion: As per FEM analysis, stainless steel brackets were a more effective method for tooth displacement andrapid canine retraction with limited anchor loss. FEM can improve suitability and efficiency of orthodontic design by enabling a multidimensional analysis.

Keywords: Ceramic Brackets; Finite Element Analysis; Stainless Steel Brackets; MBT Bracket System.

\section{Introduction}

Canine retraction refers to a deliberate posterior shift of canines to foster enhanced stability, functionality, and aesthetics. This is often achieved either by using frictional (sliding) or non-frictional (non-sliding) mechanics [1]. Sliding mechanics are generally preferred if movement of teeth is required over a relatively long distance [2]. Precluding intrusion of posteriors into the extraction space i.e. anchorage control - is an essential component of treatment design in orthodontics. Anchorage loss can be ascribed to improper anchorage preparation, excessive force, and impinge- ment of the roots of the incisors or anterior teeth to the labial cortical plate etc [3].

Orthodontic brackets are viewed as an advent of the modern medicine, however the desire for well aligned teeth has a rich history dating back to the ancient times. Metal braces composed of gold were sought after in the 1960s, which evolved into brackets being directly adhered to the teethby the 1980 . Technological advancements have catapulted innovations in the design and use of orthodontic appliances [4]. During the last decade a wide range of metal, plastic and ceramic brackets, based on the straight wire sys-

\author{
*Corresponding Author: \\ Dr. Trupti Sadhunavar, \\ Lecturer, Department of Orthodontics, KLE VK Institute of Dental Sciences, KAHER, Belagavi, India \\ Tel: 9449815111 \\ E-mail: sadhutrup@gmail.com \\ Received: September 05, 2020 \\ Accepted: October 02, 2020
}

Published: October 17, 202

Citation: Trupti Sadhunavar, Tejashri Pradhan, Sumedh Deshpande, Aarti Sethia, Kanhoba Mahabaleshwar Keluskar. A Comparative Evaluation Of Canine Retraction and Anchor Loss using Ceramic and Stainless Steel MBT Pre-adjusted Edgewise Brackets using Three Dimentional Finite Element Method. Int J Dentistry Oral Sci. 2020;7(10):854-859. doi: http://dx.doi.org/10.19070/2377-8075-20000169

Copyright: Trupti Sadhunavar ${ }^{\circ} 2020$. This is an open-access article distributed under the terms of the Creative Commons Attribution License, which permits unrestricted use, distribution and reproduction in any medium, provided the original author and source are credited. 
tem have evolved and are accessible. Pre-adjusted brackets have been reinvented several times; Andrew's straight wire appliance being the first followed by Roth's single prescription for mass correction of the dentition [5]. One such system was the MacLaughlin, Bennet and Trevisi system(MBT system) introduced by Mclaughlin, Benettand Trevisi [6]. Although ceramic brackets provide a more aesthetic solution, they are less efficient in enabling teeth movementas compared to the metal brackets [5]. Ceramic brackets also have disadvantages such as, inability to form chemical bonds with resin adhesives, low fracture toughness and an increased frictional resistance between metal arch wires and ceramic brackets $[7,8]$. Stainless steels possess desirable properties such as passivation, strong formability, ductility, weldability and wear resistance [9]. However,concerns of intergranular corrosion resistance, cytotoxicity and heat susceptibility accompany stainless steel brackets $[9,10]$. Hence, a more preemptive approach is needed to assess the suitability of these two orthodontic appliances, while ensuring patients safety and satisfaction.

In this context, FEM heralds evidence based orthodontic practice, by breaking down a complex problem into smaller constituents that are accurately measured and reconstituted to yield a more comprehensive and precise solution [11]. FEM is a numerical method for solving a differential or integral equation, particularly useful for problems with complicated geometries, loadings and material properties where analytical solutions cannot be obtained $[12,13]$. It has been experimented with in the field of medicine and dentistry, including Orthodontics, to assess stress and strain, in various biological and mechanical systems [14]. FEM presents an opportunity to non-invasively visualize and analyse the biomechanical stresses and displacement effectuated by orthodontic brackets, thereby allowing room for optimization of design.

Although comparative studies on the rate of canine retraction noted in ceramic and stainless steel brackets are available, only a few have employed finite element method (FEM) as a tool for their analysis, and have mostly focused on ceramic brackets so far.The resultant stress generated between orthodontic wires and a ceramic bracket during canine retraction remains debateable due to lack of convincing data. Hence, the aim of the study was to determine the tooth displacement and stress generated at the canine and molar regions using PEA (pre-adjusted edgewise) ceramic and metallic brackets and to compare their efficiency during canine retraction by FEM study.

\section{Materials and Methods}

\section{Study Design}

The study was conducted on a three dimensional finite element model by using the cbct with ideal conditions of first premolar extraction for orthodontic correction. The duration of this study was 8 months. Ethical clearance was obtained from the research and ethics committee at KAHER, Belagavi, Karnataka, India.

\section{Computer aided design of orthodontic brackets}

A computed tomography CBCT scanned image of the maxillary arch with first premolars extraction was acquired, following which, a finite element model of the maxilla and the teeth were simulatedusing the MIMICS software. Computer-aided design models of
E chain, metal and ceramic brackets, and 0.019 "x0.025" SS Archwire were designed. Elastomeric chain was fixed using 3-MATIC software. The ANSYS10.0 software (ANSYS Inc., Houston, PA, USA) software was employed for carrying out volumetric meshing. A force of 50 grams was applied for canine retraction with elastomeric chain using preadjusted MBT (MacLaughlin, Bennet and Trevisi system) edgewise brackets of ceramic and metallic nature. ANSYS software was used for the FEM analysis of the rate of canine retraction, anchor loss and stress generated.

\section{Simulation of stresses and displacement}

Burrstone and Grooves reported that the optimal force for individual tooth movement was $50-75$ grams [14]. Therefore, the force selected for individual canine retraction in this study was set at 50 grams $(0.5 \mathrm{~N})$ of force. This standardised force applied from the elastomeric chain for the distal movement of canine with both, the ceramic bracket and $0.019 \times 0.025$-inch stainless steel wire. Antecedent to the placement of 0.019 "x 0.025 " stainless steel wire,preliminary leveling and alignment were done using 014" round Niti wire, 016" round Niti wire, 018" round Niti wire, $17 * 25$ rectanguar NiTi wire, $19 * 25$ rectangular Niti wire and $19 * 25$ rectangular Stainless steel wire. Subsequently, the rate of canine movement and the stress distribution were analysed.

\section{Data collection and estimation}

Stress $\left(\mathrm{N} / \mathrm{mm}^{2}\right)$ was calculated and depicted as a spectrum of colours, which represented different stress levels. Red colour of the spectrum indicated a maximum principal stress and the following colours like orange, yellow, green and blue represented the reducing level of stresses while blue colour represented the lowest level of stress (Figure 1). The rate of retraction was estimated along all three planes of space by dividing the distance travelled by the time taken to achieve space closure and expressed in $\mathrm{mm}$. The extent of movement incurred in the direction opposing the direction of applied resistance was determined to be the anchorage loss observed.

\section{Results}

In the present study, deflection of beam (DMX), maximum stress (SMX), and minimum stress (SMN) along each of three dimensions i.e. $\mathrm{X}, \mathrm{Y}$ and $\mathrm{Z}$ were calculated using FEM.

The rate of canine retraction with the ceramic bracket was $0.40 \mathrm{~mm}$ along with lingual tipping and intrusion. Evaluation of the resultant stress from ceramic brackets showed maximization along the $\mathrm{X}$ axis i.e. labio-lingual orientation, reporting a von Mises stress of $2749 \mathrm{MPa}$.

The rate of canine retraction with the metallic bracket was 1.279 $\mathrm{mm}$ with von Mises stress of $3019 \mathrm{MPa}$ (Figure 4). Finite element method revealed that metal brackets impose maximum stress onthe $\mathrm{Y}$ axis i.e. mesio-distal direction (Figures 2 \& 3). Metal brackets also showed a space closure along with lingual tipping and intrusion of canine. Molar displacement was more in the $\mathrm{X}$ axis (Figure 5).

Anchor loss measured with ceramic bracket was greater along the $\mathrm{X}$ axis (Figure 6). 
Figure 1. Colour coding of stress generated.

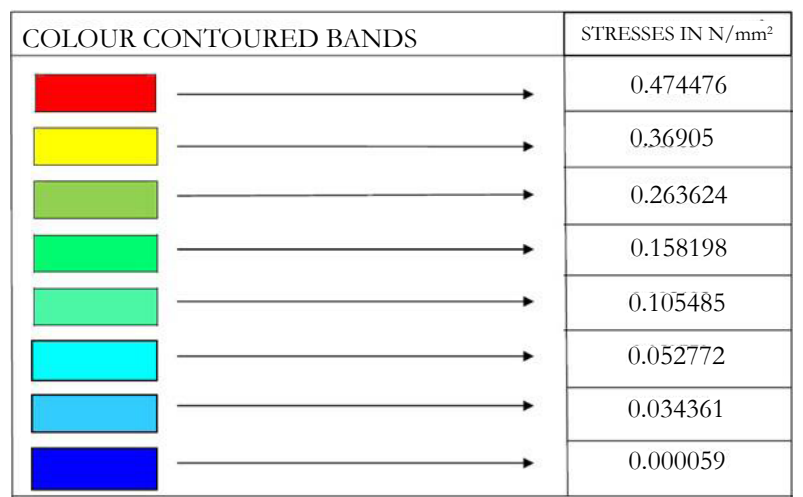

Figure 2. Principal stress observed along X, Y and Z planes by FEM study in (A) ceramic brackets (B) metal brackets.

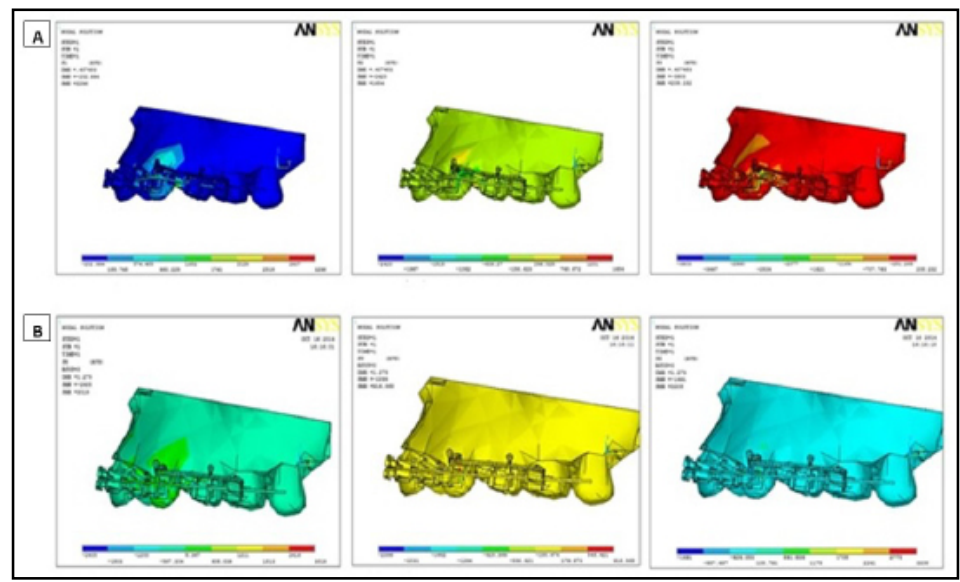

Figure 3. Stress levels observed with respect to molars in X, Y and Z planes by FEM study in (a) ceramic brackets (b) metal brackets.

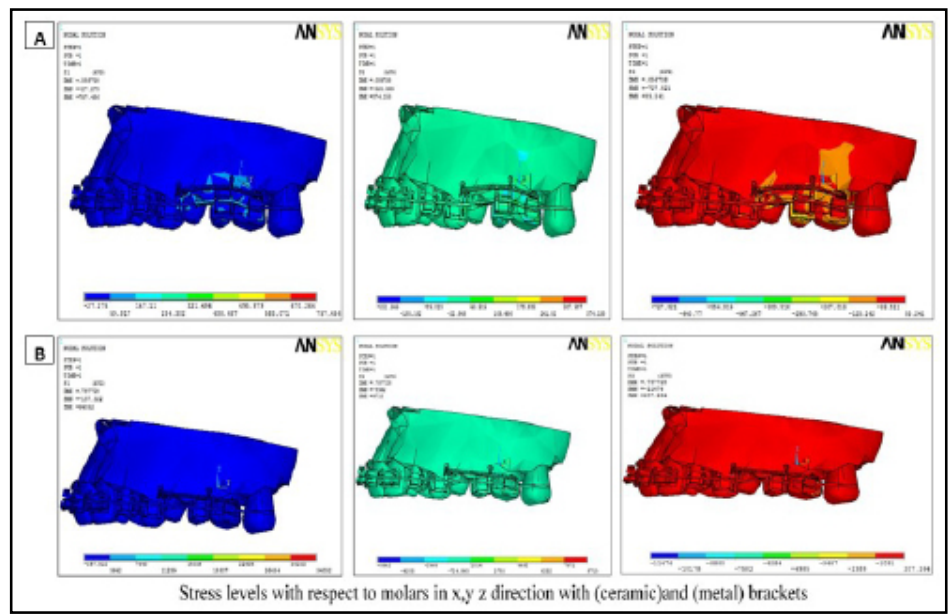

Figure 4. Von Mises stress observed by FEM study in (A) Ceramic brackets (B) Metal brackets.

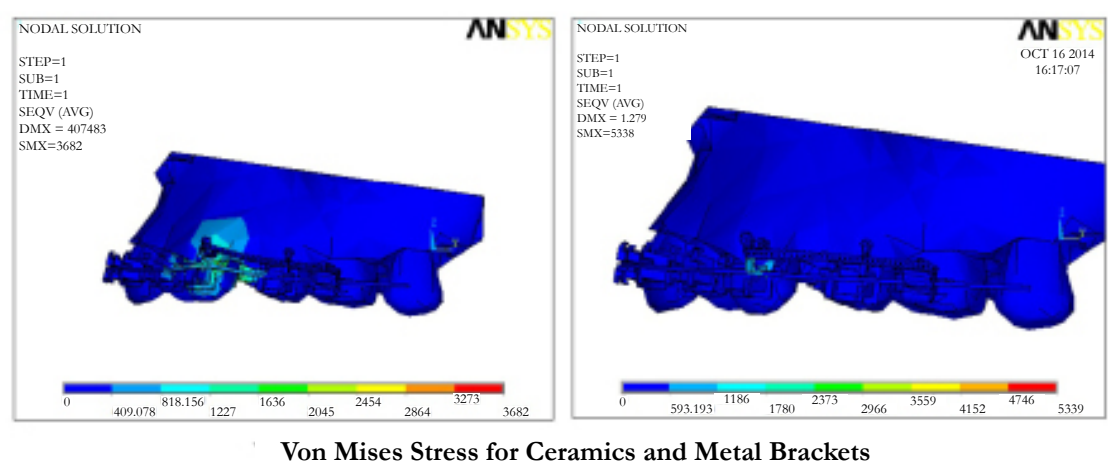


Figure 5. Total Displacement observed by FEM analysis in (A) Ceramic brackets (B) Metal brackets.

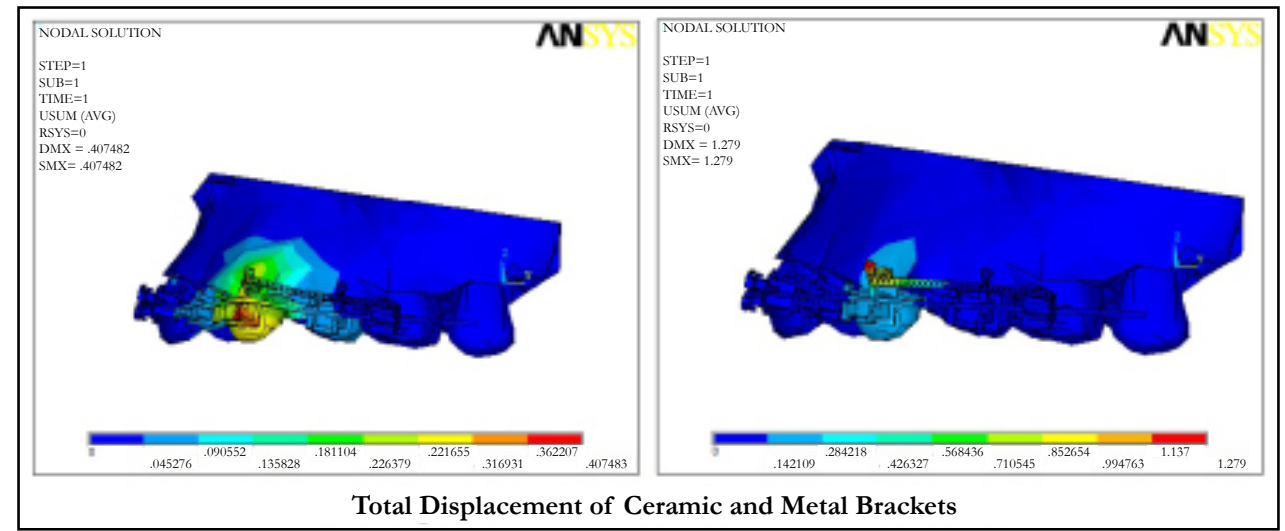

Figure 6. Displacement observed in terms of anchor loss along in X, Y and Z planes by FEM analysis in (A) ceramic brackets (B) metal brackets.

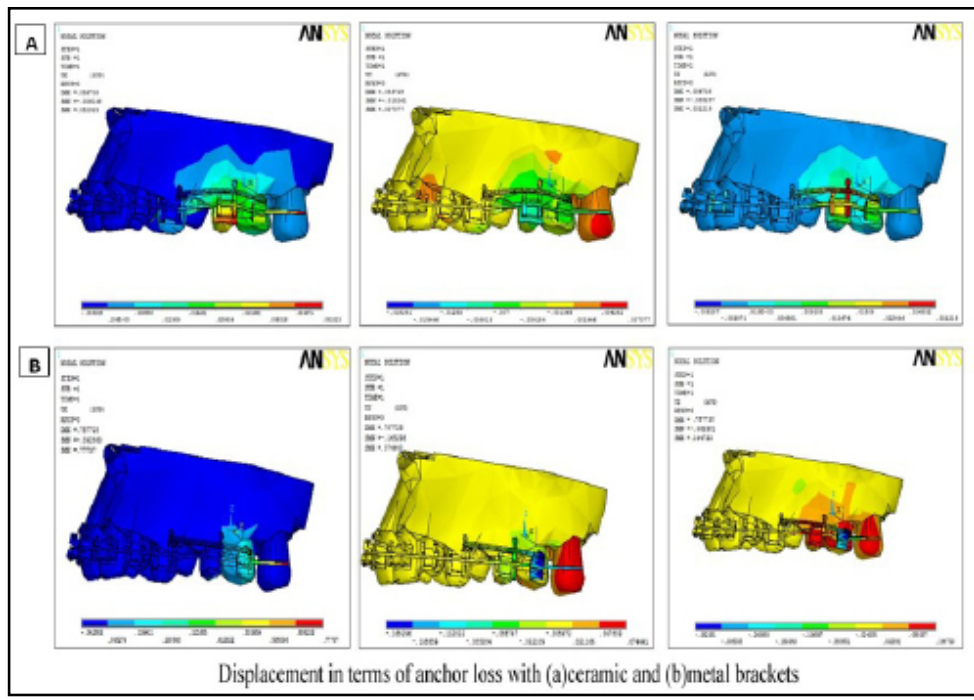

\section{Discussion}

Fixed-appliance structures constitute an integral part of modern day orthodontics and hence have elicited panoply of orthodontic studies. However, most studies in this domain canvass the efficacy and suitability post-treatment, when precious resources have already been spent. A more predictive and proactive approach is required which can provide adequate leeway for optimization of orthodontic bracket design. In this study, the rate of canine retraction, anchor loss and the stress generated during the canine retraction have been evaluated by using FEM. The stress generated was evaluated using von Mises Stress. The magnitude of stress was compared between the ceramic and metallic brackets andit was found to be a maximum in metal brackets when used for canine retraction. The stress intensities for anchoring teeth with the orthodontic bands were the highest. A generalised distribution of stresswas seen around the previously extracted premolar socket area. A higher stress was noted on the converging planes in the extraction socket.

The application of an orthodontic force results primarily in stress and strain distributions in the root of the tooth and the supporting structures, finally resulting in bone re-absorption on the compression side and bone apposition on the tension side [15]. Importantly when a tooth moves under orthodontic force, two kinds of movement are observedi.e. tipping and bodily movement. During distal tipping movement, there is a greater stress distribution in the cervical part of root than that of the apical part of the root. While in the distal translation, there is quite an even distribution of stress volume along the root surface [16]. Since the displacement pattern and speed of teeth are determined by the orthodontic force generated, the outcome of orthodontic procedures are directly influenced by the biomechanics of orthodontic structures. Therefore, the measurement of orthodontic force generated by appliance loading is imperative for proper bracket design and optimization, planning, as well as predicting efficacy of the treatment chosen [17].

In vivo monitoring of orthodontic force is riddled with procedural complexities and operational constraints [17]. Numerous in vitro force estimation techniques have been demonstrated previously. However, finite element method (FEM) uses functions based on theoretical calculations to facilitate a more meticulous and multi-variate analysis. Controllable experimental criteria, affordability, and short experimental cycle are the hallmarks of this method [18-20].

A 3-D quantitative analysis like FEM requires using a geometric model accurate both in anatomical and physical characteristics, along with a computer application. This involves the subdivision or discretization of the structure under consideration into a num- 
ber of finite sections or elements. These elements are connected at intersections called nodes [6]. A discretized complex structure or continuum usually contains many elements, which can be arranged in two or three dimensions in layers. In our study, FEM was instrumental in the precise quantification and location of stress. General distribution of stresses was apparent around the previously extracted premolar socket area, with higher stress on the converging planes. Stress intensities for anchoring teeth with the orthodontic bands were highest.

A study by Kojima et al. studied maxillary canine retraction using the FEM model, wherein on application of a constant force to the brackets the canine tipped initially but then showed steady movement [21]. This tipping of the canine was found to reduce on decreasing either the wire size or force applied. Similarly, Ammaret al. noted that as the hook length on the orthodontic bracket increases, a corresponding decline in canine PDL stress from 80 $\mathrm{kPa}$ to $22 \mathrm{kPa}$ was observed [22].

$\mathrm{Li}$ et al. presented a study on the three-dimensional finite element analysis of the mechanical stress on the root from orthodontic tooth movement by sliding mechanics and concluded that when orthodontic forces were applied to the tooth, the stress was mainly concentrated at the neck of the tooth decreasing uniformly to the apex and crown [23]. The highest stress on the root was on the cervical margin of the canine, followed by the apical region of the canine [23]. These results are congruent with the results of the present study. The stress was more at the apical region than the coronal part of tooth in both the metal as well as the ceramic brackets.It was reported in a previous study thatthe sliding force of $2 \mathrm{~N}$ was ideal to ensure the bodily orthodontic tooth movement [24]. Hence, a force higher than 50 grams was used in the present study, which would lead to bodily movement of the canine. FEM study on stress generation during rapid canine distraction carried out by Kalili et al., showed results congruent with the present study. They also mentioned the need for anchorage preservation as the stress generated was high in the molar region [25].

The stainless-steel wire $(0.019 \times 0.025$ inch SS $)$ used in the present studyacted as a stabilizer to maintain the obtained position of the canine during the earlier levelling and aligning stages of the treatment. The present study results are in concordance with the study done by Tanneet al.which reported that the amount of tooth movement produced by ceramic bracket was significantly less than the movement produced by a metal bracket [26]. The wire surfaces were scratched more obviously by ceramic brackets than by metal bracket. AlSayagh et al. concluded that the canine retraction with the standard ceramic bracket with elastomeric chain could be regarded as the best combination variable that produced less tipping [24]. In comparison,the results in present study showed that the total displacement was more with the pre adjusted edgewisemetallic brackets than the pre adjusted edgewise ceramic brackets. Even the stress on all the three-principal axes i.e. $\mathrm{X}, \mathrm{Y}$ and $\mathrm{Z}$ was more in the metallic bracket than the ceramic bracket.The friction at wire and bracket interface was more in the ceramic brackets than the metallic bracket.

The efficiency of the tooth movement was slightly lost in the ceramic bracket as compared to the metallic bracket. The loss of efficiency seems to be due to the friction at the wire and bracket interface in ceramic bracket while the friction in the metallic bracket at the wire and bracket interface was comparatively less, with more tooth displacement as indicated by the microscopic findings of the wire surfaces [28].

Anchor loss was also studied and it was observed that a very minimal stress was generated at the molar region with both metallic and ceramic brackets with almost negligible displacement. Hence, the results cannot be stated significant. But in comparison the stress generated was more at the apical region with the ceramic bracket than the metal bracket. It can be stated that the anchor loss would be greater with the ceramic bracket than the metal bracket.

Even though the results of the study concluded that the space closure was more effective with the metallic brackets, there were a few limitationsof the present study. The frictional parameters were not incorporated in the study or model design. Also predictive analysis of FEM could have been compared to outcomes observed on clinical assessment. So, these parameters can be included and evaluated in future studies. The performance of different orthodontic brackets in relation to the varying bone morphology or in patients with concomitant dental pathologies can also be investigated. The novelty of this study lies in its use of FEM, to conduct a detailed analysis of the components constituting stress and displacement in ceramic and stainless steel MBT Preadjusted Edgewise Brackets. Multidimensional observations of these two types of routinely used brackets have been brought to fore their benefits and deficiencies, that must be considered while establishing suitability, and creating novel designs.

\section{Conclusion}

The rate of canine retraction between preadjusted edgewise ceramic and conventional metallic brackets highlighted a clinical difference. It was observed that the retraction was maximum with metal bracket in all the three planes compared to the ceramic bracket. Metallic brackets proved to be more efficient in the closure of space. Frictional values are high for the ceramic bracket when compared to the metallic bracket. The use of FEM demonstrated that the amount of orthodontic force required to move a tooth depends upon the amount of friction created. Selection of material with a low coefficient of friction is required to optimize the treatment. Hence, it is recommended that orthodontic appliances must first be evaluated by FEM to adjudge its suitability following which clinical trials are recommended. As FEM is a building foundation to any innovation, so as not to compromise the treatment progress and provide a more fructuous outcome.

\section{Refereces}

[1]. Kulshrestha RS, Tandon R, Chandra P. Canine retraction: A systematic review of different methods used. J Orthod Sci. 2015; 4(1):1-8. PMID: 25657985.

[2]. Abu-Shahba R, Alassiry A. Comparative evaluation of the maxillary canine retraction rate and anchorage loss between two types of self-ligating brackets using sliding mechanics. J Orthodont Sci. 2019; 8:3. PMID: 31001495.

[3]. Creekmore TD, Eklund MK. The possibility of skeletal anchorage. J ClinOrthod. 1983; 17(4): 266-9. PMID: 6474142.

[4]. Gemmi C. A Brief History of Orthodontics [Internet]. Orthodontics Limited. 2018 [cited 25 August 2020]. Available from: https://www.orthodonticslimited.com/orthodontics/orthodontics-history/\#: - :text=By\%20the\%20 1960s\%20gold\%20was,to\%20be\%20used\%20a\%20lot.

[5]. Talapaneni AK, Supraja G, Prasad M, Kommi PB. Comparison of sagittal and vertical dental changes during first phase of orthodontic treatment with MBT vs ROTH prescription. Indian J Dent Res. 2012; 23: 182-6. PMID: 


\section{7.}

[6]. Padmaraj AV, Kapila S, Duncausan MG, Nanda RS. Evaluation of friction between ceramic brackets and orthodontic wires of four alloys. Am J Orthod and Dentofac Orthop. 1990; 98: 499-506. PMID: 2248227.

[7]. Karamouzos A, Athanasiou AE, Papadopoulos MA. Clinical characteristics and properties of ceramic brackets: A comprehensive review. Am J. Orthod Dentofacial Orthop. 1997; 112: 34-40. PMID: 9228839.

[8]. Halimia A, Doukkalib HBA, Azeroualc MF, Zaouia F. A systematic review of force decay in orthodontic elastomeric power chains. International Orthodontics. 2012; 10(3): 223-240. PMID: 22906378.

[9]. Arango Santiago, Ossa Claudia. Stainless Steel: Material Facts for the Orthodontic Practitioner. RevistaNacional de Odontología. 2015; 11(20): 73-82.

[10]. Oh KT, Choo SU, Kim KM, Kim KN. A stainless steel bracket for orthodontic application. Eur J Orthod. 2005; 27(3): 237-244. PMID: 15947222.

[11]. Singh JR, Kambalyal P, Jain M, Khandelwal P. Revolution in Orthodontics: Finite element analysis. J Int Soc Prev Community Dent. 2016; 6(2):110114. PMID: 27114948.

[12]. Penedo ND, Elias CN, Pacheco MCT, de Gouvea JP. 3D simulation of orthodontic tooth movement. Dental Press J Orthod. 2010; 15(5): 98-108.

[13]. Dixit US. Finite Element Method: An introduction [Internet]. Department of Mechanical Engineering, Indian Institute of Technology Guwahati-781039, India. [Cited on 21st April 2020] Available from: http://www. iitg.ac.in/engfac/rtiwari/resume/usdixit.pdf

[14]. Burrstone CJ, Grooves MH. Threshold and optimum force values for maxillary anterior tooth movement. J Dent Res. 1960; 39: 694.

[15]. Liou EJ, Huang CS. Rapid canine retraction through distraction of the periodontal ligament. Am J Orthod Dentofacial Orthop. 1998; 114(4): 372-82. PMID: 9790320.

[16]. Jing Y, Han XL, Cheng BH, Bai D. Three-dimensional FEM analysis of stress distribution in dynamic maxillary canine movement. Chinese Sci Bulletin. 2013; 58: 2454-9.

[17]. Zhou X, Gan Y, Zhao Q, Xiong J, Xia Z. Simulation of orthodontic force of archwire applied to full dentition using virtual bracket displacement method. Int J Numer Method Biomed Eng. 2019; 35(5): e3189.

[18]. Zhang Z, Chen J, Li E, Li W, Swain M, Li Q. Topological design of all-ceramic dental bridges for enhancing fracture resistance. Int J Numer Methods Biomed Eng. 2016; 32(6): e02749. PMID: 26444905.
[19]. Zhang D, Han X, Zhang Z, Jie Liu, Chao Jiang, Nobuhiro Yoda, et al. Identification of dynamic load for prosthetic structures. Int J Numer Methods Biomed Eng. 2017; 33(12): 12. PMID: 28425209.

[20]. Cheng Y, Lin D, Jiang C, Lin Y. Dental implant customization using numerical optimization design and 3-dimensional printing fabrication of zirconia ceramic. Int J Numer Methods Biomed Eng. 2017; 33(5): 1-12. PMID: 27539228.

[21]. Kojima Y, Fukui H. Numerical simulation of canine retraction by sliding mechanics. Am J Orthod Dentofacial Orthop. 2005; 127(5): 542-551. PMID: 15877034

[22]. Ammar HH, Ngan P, Crout RJ, Mucino VH, Mukdadi OM. Three-dimensional modeling and finite element analysis in treatment planning for orthodontic tooth movement. Am J Orthod Dentofacial Orthop. 2011; 139(1): e59-e71. PMID: 21195258.

[23]. Li P, Mao J, Peng Z. Three-dimensional finite element analysis of the mechanical stress on root from orthodontic tooth movement by sliding mechanics. J HuazhongUniv Sci Technolog Med Sci. 2007; 27(6): 745-7. PMID: 18231760.

[24]. Reitan K. Clinical and histological observations on tooth movement during and after orthodontic treatment. Am J Orthod Dentofacial Orthop. 1967; 53: 721-45. PMID: 5233926.

[25]. Kalili T, Caputo A, Lai E, Nishimura, Ichiro, Gordillo P. Stress generated by laminated aligners for class iii mandibular distraction. Paper presented at: COAST: Conferences on Orthodontic Advances in Science and Technology. 2008.

[26]. Tanne K, Matsubara S, Shibaguchi T, Sakuda M. Wire friction from ceramic brackets during simulated canine retraction. Angle Orthod. 1991; 61(4): 285-90. PMID: 1763839.

[27]. Al-Sayagh NM, Ismael AJ. Evaluation of Canine Tipping During its Retraction with Sliding Mechanics. (An in Vitro Study) Al - Rafidain Dent J. 2012; 12(1): 43-51.

[28]. Guerrero AP, Filho OG, Tanaka O, Camargo ES, Vieira S. Evaluation of frictional forces between ceramic brackets and archwires of different alloys compared with metal brackets. Braz Oral Res. 2010; 24(1): 40-5. PMID: 20339712. 